\title{
Atrioventricular block response to exercise and intraventricular conduction at rest
}

\author{
S. D. Moulopoulos, J. Darsinos, and D. A. Sideris \\ From the Department of Clinical Therapeutics, School of Medicine, University of Athens, Greece
}

Sixty patients with atrioventricular block were exercised and monitored by a radioelectrocardiograph. Cases with a bundle-branch block $Q R S$ pattern at rest presented an improvement of atrioventricular conduction on exercise in 12.5 per cent, no change in 43.8 per cent, and an impairment in 43.8 per cent of cases. Corresponding figures in cases with no intraventricular conduction defect were 61.4 per cent, $24^{\circ} 0$ per cent, and 13.6 per cent $(P<0.001)$.

Heart rate, neural tone, and myocardial ischaemia in relation to the refractory period length and the localization of the lesion are considered as factors possibly accounting for the difference in response to exercise between the two groups.

Changes of the degree of atrioventricular block on effort have been observed by several authors (Scherf and Dix, 1952; Manning and Sears, 1962). Moulopoulos and Anthopoulos (1968) studied such changes in relation to atrial rate using a radioelectrocardiograph. The presence or absence of bundle-branch block at rest appears to be associated with the response of AV block to exercise.

Clinical studies (Damato et al., 1969a, b) have suggested the differentiation of AV block in two types according to the location of the conduction defect above or below the bundle of His. Block of both bundle-branches is related to AV block below the bundle of His.

In the present study an attempt is made to investigate whether intraventricular conduction defects at rest are in any way related to the response of $\mathrm{AV}$ block to exercise.

\section{Subjects and method}

Thirty-eight men and 22 women of 17 to 90 years of age with several degrees of AV block were exercised, while their electrocardiogram was continuously recorded using a radioelectrocardiograph. ${ }^{1}$ The patients were asked to walk a 50 metres distance and then walk upstairs a total of 30 steps. They were stopped if either symptoms (dyspnoea, angina, or dizziness) or obvious deterioration in AV conduction appeared. In the statistical analysis of the results ( $\chi^{2}$ method) the 5 per cent significance level was considered as significant.

Received 9 February 1972.

${ }^{1}$ RKG I00A Telemedics, Southampton, Pennsylvania, U.S.A.

\section{Findings}

The degree of AV block, the PR interval (whenever this was constant), the QRS duration, and the atrial and the ventricular rate of the 60 patients at rest and during maximum exercise are given in Table 1 . Incidental arrhythmias, like atrial or ventricular ectopic beats, and transitional states were not included in the data of this Table. All measurements were made from portions of the tracing representing a steady state.

The patients were divided into two groups according to the duration of the QRS complexes at rest. Group I (44 cases) was characterized by QRS complexes of less than 0.11 sec duration. Group 2 (I6 cases) consisted of those with a QRS complex of $0 \cdot 12 \mathrm{sec}$ or more.

Table 2 summarizes the distribution of different degrees of $\mathrm{AV}$ block in the 2 groups at rest. No statistically significant difference between the 2 groups as to the degree of $\mathrm{AV}$ block was present so that the populations of the 2 groups may be treated as identical in this respect.

Table 3 summarizes the response of $\mathrm{AV}$ block to exercise in the 2 groups. According to the response to exercise each group was divided into 3 subgroups: A, improvement; $B$, no change; and C, impairment of AV conduction. The classification into subgroups was made according to the type of change of $\mathrm{AV}$ conduction in response to exercise.

In group $\mathrm{I}$, an improvement of $\mathrm{AV}$ conduction during exercise (subgroup IA) was noted in 27 cases $(6 \mathrm{I} \cdot 4 \%$ ), no change (sub- 
TABLE I

\begin{tabular}{|c|c|c|c|c|c|c|c|c|c|}
\hline \multirow{2}{*}{$\begin{array}{l}\text { Case } \\
\text { No. }\end{array}$} & \multicolumn{4}{|l|}{ Before exercise } & \multicolumn{5}{|c|}{ During exercise } \\
\hline & $\begin{array}{l}\text { AV block } P R \\
\text { degree }\end{array}$ & $Q R S$ & $\begin{array}{l}\text { Atrial } \\
\text { rate }\end{array}$ & $\begin{array}{l}\text { Ventr. } \\
\text { rate }\end{array}$ & $\begin{array}{l}\text { AV block } \\
\text { degree }\end{array}$ & $P R$ & $Q R S$ & $\begin{array}{l}\text { Atrial } \\
\text { rate }\end{array}$ & $\begin{array}{l}\text { Ventr. } \\
\text { rate }\end{array}$ \\
\hline
\end{tabular}

\section{Group IA}

$\begin{array}{rr}\text { I } & \text { I } \\ 2 & \text { I } \\ 3 & \text { I } \\ 4 & \text { I } \\ 5 & \text { I } \\ 6 & \text { I } \\ 7 & \text { I } \\ 8 & \text { I } \\ 9 & \text { I } \\ \text { I0 } & \text { I } \\ \text { II } & \text { I } \\ 12 & \text { I } \\ 13 & \text { I } \\ \text { 14 } & \text { I } \\ 15 & \text { I } \\ 16 & \text { II } \\ \text { I7 } & \text { II } \\ 18 & \text { II } \\ \text { 19 } & \text { II } \\ 20 & \text { II } \\ 21 & \text { III } \\ 22 & \text { III } \\ 23 & \text { III } \\ 24 & \text { III } \\ 25 & \text { III } \\ 26 & \text { III } \\ 27 & \text { III } \\ & \end{array}$

$\begin{array}{lll}0.22 & 0.07 & 50 \\ 0.22 & 0.08 & 65 \\ 0.24 & 0.08 & 82 \\ 0.24 & 0.08 & 85 \\ 0.24 & 0.09 & 68\end{array}$

50 Normal

$0.26 \quad 0.10$

0.26

0.28

0.28

0.30

0.26

0.26

0.28

0.30

Wen.

$$
0.09
$$

90

$0.07 \quad 60$

$0.08 \quad 75$

$\begin{array}{ll}0.07 & 67\end{array}$

$0.10 \quad 83$

$0.08 \quad 96$

$0.07 \quad 68$

0.06

II Wen.

0.11

Wen. 0.08

$0.18 \quad 0.09$

0.18

\subsection{8}

$0.07 \quad 72$

$0.08 \quad 93$

$0.09 \quad 87$

$0.10 \quad 104$

$0.08 \quad 98$

$\begin{array}{ll}0.09 & 83 \\ 0.07 & 72\end{array}$

65
82
85
68
72
83
90
60
75
67
83
96
68
70
57
70
56
45
40
58
36
45
42
38
47
58

Normal

Normal

Normal

Normal

Normal

Normal

Normal

Normal

Normal I

I

I

Normal

I

I

I

I

Normal

Normal

I

II

II

$\begin{array}{lrrr}0.17 & 0.07 & 93 & 93 \\ 0.16 & 0.08 & 100 & 100 \\ 0.18 & 0.08 & 112 & 112 \\ 0.20 & 0.08 & 128 & 128 \\ 0.20 & 0.09 & 100 & 100 \\ 0.18 & 0.08 & 150 & 150 \\ 0.18 & 0.10 & 134 & 134 \\ 0.16 & 0.09 & 120 & 120 \\ 0.20 & 0.07 & 90 & 90 \\ 0.18 & 0.08 & 115 & 115 \\ 0.18 & 0.07 & 98 & 98 \\ 0.22 & 0.10 & 146 & 146 \\ 0.24 & 0.08 & 134 & 134 \\ 0.24 & 0.07 & 90 & 90 \\ 0.22 & 0.06 & 106 & 106 \\ 0.20 & 0.11 & 112 & 112 \\ 0.26 & 0.07 & 122 & 122 \\ 0.24 & 0.08 & 108 & 108 \\ 0.24 & 0.09 & 114 & 114 \\ 0.28 & 0.08 & 103 & 103 \\ 0.20 & 0.07 & 110 & 110 \\ 0.18 & 0.08 & 118 & 118 \\ 0.20 & 0.09 & 100 & 100 \\ 0.28 & 0.10 & 120 & 120 \\ W e n . & 0.08 & 117 & 78 \\ \text { Wen. } & 0.09 & 120 & 90 \\ 0.20 & 0.07 & 110 & 55 \\ & & & \end{array}$

Group IB

$\begin{array}{ll}28 & \text { I } \\ 29 & \text { I } \\ 30 & \text { II } \\ 3 \text { I } & \text { II } \\ 32 & \text { III } \\ 33 & \text { III } \\ 34 & \text { III } \\ 35 & \text { III } \\ 36 & \text { III } \\ 37 & \text { III } \\ 38 & \text { III }\end{array}$

$\begin{array}{ll}\text { I } & 0.24 \\ \text { I } & 0.26 \\ \text { II } & 0.20\end{array}$

$\begin{array}{llll}0.08 & 56 & 56 & \text { I } \\ 0.10 & \mathbf{7 2} & \mathbf{7 2} & \text { I } \\ 0.09 & \mathbf{7 8} & 39 & \text { II } \\ 0.07 & 84 & \mathbf{4 2} & \text { II } \\ 0.08 & \mathbf{7 6} & 32 & \text { III } \\ 0.08 & 87 & 44 & \text { III } \\ 0.10 & 86 & 38 & \text { III } \\ 0.09 & 97 & 47 & \text { III } \\ 0.08 & 83 & 36 & \text { III } \\ 0.08 & 79 & 42 & \text { III } \\ 0.08 & 90 & 36 & \text { III }\end{array}$

$\begin{array}{rrrr}0.24 & 0.08 & 108 & 108 \\ 0.26 & 0.10 & 128 & 128 \\ 0.20 & 0.09 & 116 & 58 \\ 0.18 & 0.07 & 120 & 60 \\ & 0.08 & 94 & 38 \\ & 0.08 & 106 & 48 \\ & 0.10 & 115 & 40 \\ & 0.09 & 126 & 47 \\ & 0.08 & 120 & 36 \\ & 0.08 & 106 & 48 \\ & 0.08 & 112 & 34\end{array}$

Group IC

\begin{tabular}{|c|c|c|c|c|c|c|c|c|c|c|}
\hline $\begin{array}{l}39 \\
40\end{array}$ & $\begin{array}{l}\text { Normal } \\
\text { Normal }\end{array}$ & $\begin{array}{l}0.16 \\
0.18\end{array}$ & $\begin{array}{l}0.10 \\
0.08\end{array}$ & $\begin{array}{l}76 \\
68\end{array}$ & $\begin{array}{l}76 \\
68\end{array}$ & $\begin{array}{l}\text { II } \\
\text { II }\end{array}$ & $\begin{array}{l}\text { Wen. } \\
0.18\end{array}$ & $\begin{array}{l}0.10 \\
0.08\end{array}$ & $\begin{array}{l}116 \\
120\end{array}$ & $\begin{array}{l}87 \\
60\end{array}$ \\
\hline $4 I$ & I & 0.24 & 0.09 & 72 & 72 & II & $0 \cdot 20$ & 0.09 & 130 & 65 \\
\hline 42 & II & Wen. & 0.09 & 94 & 72 & III & & 0.09 & 124 & 56 \\
\hline 43 & II & 0.18 & 0.07 & 104 & 52 & III & & 0.07 & 120 & 54 \\
\hline 44 & II & 0.20 & 0.10 & 86 & 43 & III & & 0.10 & I IO & 40 \\
\hline
\end{tabular}

Group $2 A$

$\begin{array}{rllllllllll}45 & \text { I } & 0.24 & 0.12 & 57 & 57 & \text { Normal } & 0.20 & 0.12 & 98 & 98 \\ 46 & \text { II } & 0.20 & 0.12 & 92 & 46 & \text { II } & \text { Wen. } & 0.12 & \text { I20 } & 80\end{array}$

Group $2 B$

\begin{tabular}{lllrllllrrr}
47 & I & 0.22 & 0.13 & 94 & 94 & I & 0.22 & 0.13 & 118 & 118 \\
48 & II & 0.22 & 0.12 & 82 & $4 I$ & II & 0.22 & 0.12 & 106 & 53 \\
49 & III & & 0.12 & 96 & 32 & III & & 0.12 & 112 & 32 \\
50 & III & & 0.13 & 105 & 36 & III & & 0.13 & 128 & 38 \\
5 I & III & & 0.13 & 78 & 44 & III & & 0.13 & 98 & 42 \\
52 & III & & 0.12 & 108 & 33 & III & & 0.12 & 116 & 33 \\
53 & III & & 0.12 & 85 & 33 & III & & 0.12 & 104 & 35 \\
\hline
\end{tabular}

I, II, III = Corresponding degrees of AV block. Wen. = Wenckebach periods. Normal = Normal AV conduction. 
TABLE I-cont.

\begin{tabular}{|c|c|c|c|c|c|c|c|c|c|c|}
\hline \multirow{2}{*}{$\begin{array}{l}\text { Case } \\
\text { No. }\end{array}$} & \multicolumn{5}{|c|}{ Before exercise } & \multicolumn{5}{|c|}{ During exercise } \\
\hline & $\begin{array}{l}\text { AV block } \\
\text { degree }\end{array}$ & $P R$ & $Q R S$ & $\begin{array}{l}\text { Atrial } \\
\text { rate }\end{array}$ & $\begin{array}{l}\text { Ventr. } \\
\text { rate }\end{array}$ & $\begin{array}{l}\text { AV block } \\
\text { degree }\end{array}$ & $P R$ & $Q R S$ & $\begin{array}{l}\text { Atrial } \\
\text { rate }\end{array}$ & $\begin{array}{l}\text { Ventr. } \\
\text { rate }\end{array}$ \\
\hline \multicolumn{11}{|c|}{ Group $2 C$} \\
\hline 54 & I & $0-0.28$ & $\begin{array}{l}0.08 \text { and } \\
0.12\end{array}$ & $45-100$ & $45-100$ & II & Wen. & 0.12 & 100 & 80 \\
\hline 55 & II & Wen. & 0.12 & 90 & 60 & II & 0.18 & 0.12 & 130 & 65 \\
\hline 56 & II & Wen. & 0.12 & 84 & 56 & II & 0.20 & 0.12 & 118 & 59 \\
\hline 57 & II & 0.18 & 0.14 & 86 & 43 & II & & 0.14 & 122 & 50 \\
\hline 58 & II & 0.20 & 0.13 & 92 & 46 & II & & 0.13 & 136 & 52 \\
\hline 59 & II & 0.20 & 0.12 & 100 & 50 & III & & 0.12 & 138 & 48 \\
\hline 60 & II & 0.22 & 0.13 & 78 & 34 & III & & 0.13 & 100 & 34 \\
\hline
\end{tabular}

group IB) in II cases $(25.0 \%)$, and an impairment (subgroup IC) in 6 cases (13.6\%). In group 2 corresponding figures were subgroup 2A: 2 cases (12.5\%), subgroup 2B: 7 cases $(43.8 \%)$, and subgroup $2 \mathrm{C}: 7$ cases $(43.8 \%)$. The difference between groups $\mathrm{I}$ and 2 concerning the response of AV block to exercise was highly significant $(P<0.001)$.

No connexion was observed between the effect of exercise on AV conduction and the type of bundle-branch block (left bundlebranch block pattern 5 cases; right bundlebranch block pattern II cases).

Three cases showing particular features of impulse conduction are analysed below.

Case 54 A man of 82 with possible coronary arteriosclerosis had a heart rate ranging between 45 and 100 a minute at rest (Fig. I, upper row). $\mathbf{P}$ waves with varying configuration, indicating their multiple origin, were present at the tracing. The QRS complexes were either of normal duration or had a left bundle-branch block pattern. The PR interval varied also from 0 to $0.28 \mathrm{sec}$, with rare instances of a $P$ wave following the QRS. QRS complexes with a normal pattern were preceded by long $R R$ intervals ( $I .08$ to $I \cdot 20 \mathrm{sec}$ ) and by short PR intervals (0 to $0.22 \mathrm{sec}$ ). QRS complexes with a left bundle-branch block pat-

TABLE 2 Distribution of degrees of $A V$ block in groups $I$ and 2.

\begin{tabular}{llrrrr}
\hline & \multicolumn{2}{l}{ Degree of $A V$ block } & \multicolumn{2}{c}{ Total } \\
\cline { 2 - 5 } & Normal & \multicolumn{1}{c}{$I$} & $I I$ & $I I I$ & \\
\hline Group 1 & 2 & 18 & 10 & 14 & 44 \\
Group 2 & 0 & 3 & 8 & 5 & 16 \\
\hline Total & 2 & 21 & 18 & 19 & 60 \\
\hline
\end{tabular}

Normal $=$ Normal AV conduction. I, II, III = Corresponding degrees of AV block. tern were preceded by short $R R$ intervals ( 0.60 to $0.92 \mathrm{sec})$ and long PR intervals $(0.22$ to 0.28 $\mathrm{sec})$. $R R$ intervals of intermediate duration (0.94 to $I .06 \mathrm{sec}$ ) were associated with both long and short PR intervals and corresponding QRS patterns. On exercise, while the $P$ wave configuration, and the PP and PR intervals were still varying from beat to beat, a mean ventricular rate of 95 a minute was achieved. At this rate all QRS complexes with very few exceptions were of the left bundle-branch block pattern. Though the PR interval varied from beat to beat (range 0.24 to $0.40 \mathrm{sec}$ ), rare instances of a progressive prolongation of the PR interval ending in a dropped beat were present (Fig. I, lower row).

Case I A 72-year-old man presented with AV block of unknown aetiology (Fig. 2) and AdamsStokes attacks. His ordinary ventricular complexes were of normal pattern. During his attacks of unconsciousness ventricular arrest was recorded while the atrial rate increased progressively. When the latter became 100 to 120 a minute a I:I AV conduction was suddenly established. The heart rate was then slowly reduced. Once it reached 75 to 80 a minute complete AV block with ventricular asystole was established and this cycle was repeated. Isoprenaline per os stopped the AdamsStokes attacks. An effort test on the radioelectrocardiograph showed a shortening of $P R$ intervals together with the tachycardia produced by exer-

TABLE 3 Division of Groups $I$ and 2 into subgroups $A, B$, and $C$, according to effect of exercise on $A V$ conduction.

\begin{tabular}{lllll}
\hline & \multicolumn{2}{l}{ Subgroups } & Total \\
\cline { 2 - 5 } & $\begin{array}{l}\text { A. Improve- } \\
\text { ment }\end{array}$ & $\begin{array}{l}\text { B. No } \\
\text { change }\end{array}$ & $\begin{array}{l}\text { C. Impair- } \\
\text { ment }\end{array}$ \\
\hline Group I & 27 & 11 & 6 & 44 \\
Group 2 & 2 & 7 & 7 & 16 \\
\hline Total & 29 & 18 & 13 & 60 \\
\hline
\end{tabular}




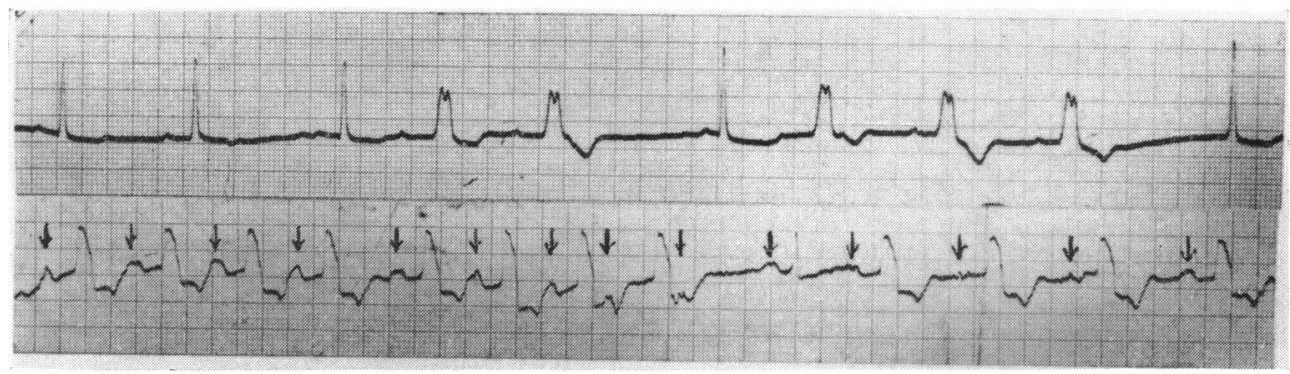

FIG. I Electrocardiogram of Case 54. Upper row at rest. Lower row at maximal exercise. Arrows indicate the $P$ waves.

cise. Thus, at a heart rate of 50 a minute at rest, the PR interval was $0.22 \mathrm{sec}$, while at a heart rate of 93 a minute during exercise, $P R$ was 0.17 sec.

Case 60 A 62-year-old man presented with AV block of unknown aetiology (Fig. 3). In most instances he had complete AV block with an idioventricular rhythm. The ventricular ectopic focus was probably situated in the left ventricle as judged by a right bundle-branch block configuration of the QRS complexes. The idioventricular rhythm was regular with a $R R$ interval of $I \cdot 76$ sec both at rest and on exercise. Occasionally, however, ventricular complexes appeared of a configuration distinctly different from the former in spite of a right bundle-branch block pattern. These complexes always followed a constant PR interval of 0.20 to $0.22 \mathrm{sec}$, with the exception of Fig. 3D. They occurred either just before the anticipated idioventricular beats or approximately $0.60 \mathrm{sec}$ after the previous $\mathrm{QRS}$ (i.e. just after the T wave, Fig. 3B, C, and E). Because of these features these complexes were considered as being sinus in origin and transmitted to the ventricles via the left branch of the His bundle. The 'prematurely' conducted beats of Fig. $3 \mathrm{~B}$, $\mathrm{C}$, and $\mathrm{E}$ were considered as occurring during the supernormal conduction phase.

At rest, with PP intervals of 0.76 to $0.80 \mathrm{sec}$, $P$ waves occurring as early as $\mathbf{I} \cdot 36 \mathrm{sec}$ from the previous QRS were conducted to the ventricles (Fig. 3A). On exercise, with PP intervals of 0.60 $\mathrm{sec}, \mathrm{P}$ waves occurring as late as $\mathbf{I} \cdot 56 \mathrm{sec}$ (third arrow) from the previous $Q R S$ were not conducted to the ventricles (Fig. 3B). On exercise the only beats conducted to the ventricles were the ones occurring at the supernormal phase of conduction. After the 'prematurely' conducted beats orthograde conduction appeared to be restored earlier than after an idioventricular beat or a normally conducted beat. Thus, in Fig. $3 C$, a $P$ wave occurring $\mathrm{I} \cdot 22 \mathrm{sec}$ after the beginning of the supernormally conducted $Q R S$ complex was conducted to the ventricles, while on the same tracing a $P$ wave occurring I.40 sec after the first QRS complex (idioventricular beat) was not conducted. Similarly, in Fig. 3E, P wave No. 4, after a 'pre- mature' beat was conducted to the ventricles, though the preceding RP interval $(\mathrm{I} \cdot 32 \mathrm{sec})$ was shorter than that of $P$ waves No. 6 and II (I.36 sec) which were not conducted.

\section{Discussion}

The relation between bundle-branch block and the response of AV conduction to exercise may be of clinical and theoretical importance. Reading a rest electrocardiogram with AV block one may anticipate with some probability the response to ordinary exercise.

An impairment of $\mathrm{AV}$ conduction during exercise may be compared with the impairment of the conduction via a branch of the His bundle in cases with intermittent bundlebranch block (Burch, 1962; Bauer, 1964). Bundle-branch block appears when the cardiac cycle becomes shorter than the refractory period of the bundle-branch, due to excessive

FIG. 2 Electrocardiogram of Case I.

Continuous tracing.

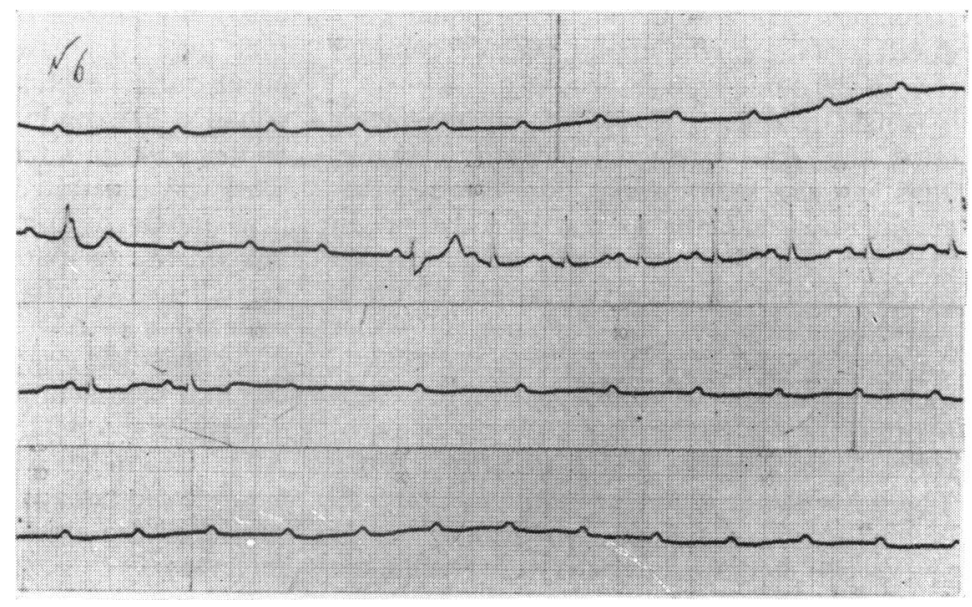




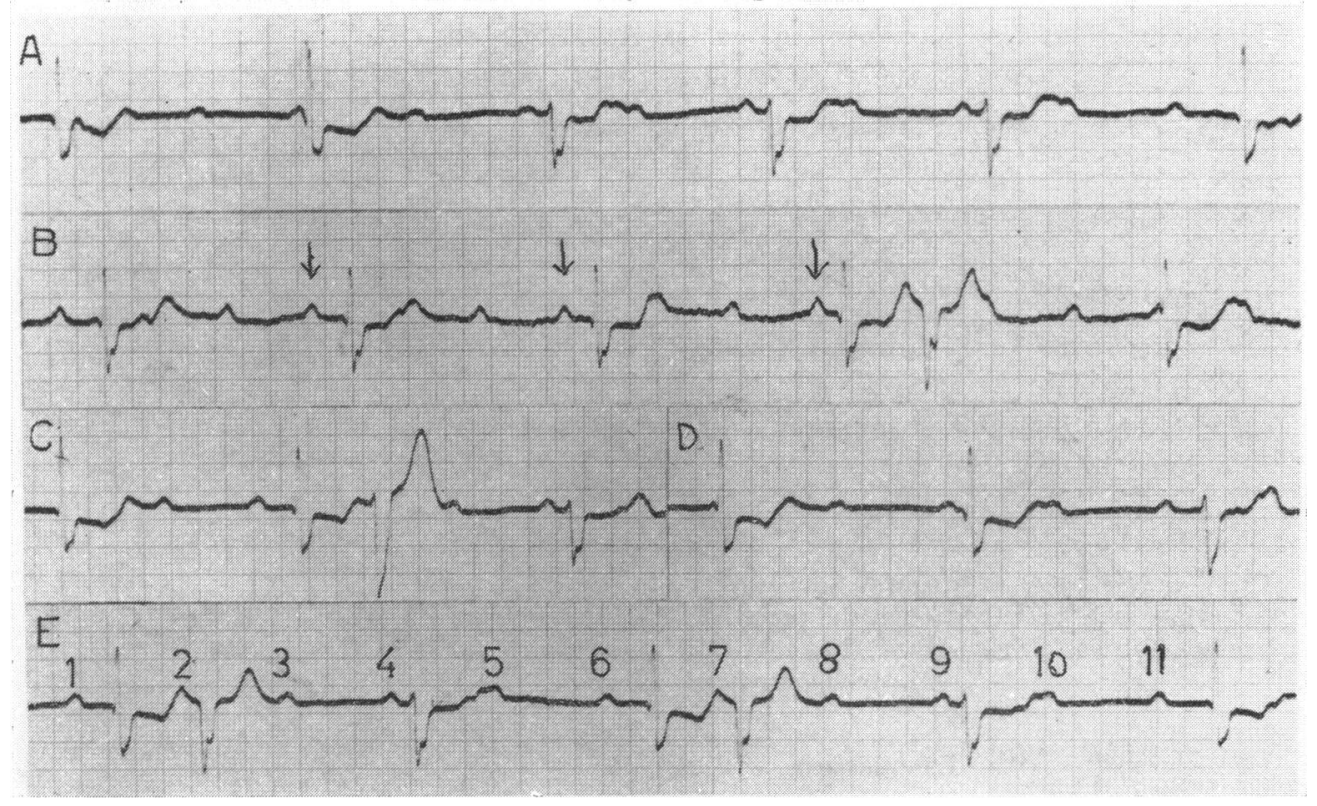

FIG. 3 Five samples of the electrocardiogram of Case 60. (A) At rest, with an atrial rate of $77 /$ min, $A V$ conduction occurs after RP intervals as short as $1 \cdot 36 \mathrm{sec}$. Short period of 2:I AV block (3 ventricular complexes). (B) On effort, with an atrial rate of $97 /$ min, there is no $A V$ conduction after $R P$ intervals as long as $I \cdot 48, I \cdot 50$, and $I \cdot 56 \mathrm{sec}$ (arrows). (C) After the short $R R$ interval imposed by the 'premature' beat, $A V$ conduction occurs after an RP interval of only $I \cdot 22 \mathrm{sec}$. (D) After an RP interval of $I \cdot 36 \mathrm{sec}, A V$ conduction occurs with a long $P R$ $(0.30 \mathrm{sec})$. (E) Four conducted beats, all of the same configuration, after $P$ waves designated by the numbers $2,4,7$, and 9. $P$ wave 4 is conducted though the preceding $R P$ interval $(I \cdot 32 \mathrm{sec})$ is shorter than that of $P$ waves 6 and II $(I \cdot 36 \mathrm{sec})$ which are not conducted to the ventricles. Note that all 'premature' beats on $B, C$, and $E$ are of the same configuration as the conducted ones (e.g. $E_{4}$ and $\left.E_{9}\right)$ and are always preceded by a $P$ wave, denoting their sinus origin.

tachycardia, especially paroxysmal, or to excessive lengthening or the refractoriness of the Purkinje fibres, as in some myocardial diseases. A cardiac cycle shorter than the refractory period of the atrioventricular conducting tissue might impair the AV conduction in the same way.

A fast rate may, therefore, be one factor impairing $\mathrm{AV}$ conduction during exercise. This was also seen during spontaneous changes in rate occurring at rest in Case 54. In this case the PR interval may be influenced by two factors. The varying origin of the $P$ waves might affect the $P R$ interval either through the different distance of the ectopic foci from the AV node or possibly by competition for the conducting pathway or pathways (Moe, Preston, and Burlington, 1956). The other factor seems to be the RR interval length, since, in general, whether at rest or on exercise, long RR intervals were terminated in a short PR interval and a narrow $Q R S$ complex and vice versa.

Neural factors could be the cause of the improved AV conduction during exercise. It is classically known that increased sympathetic tone and decreased vagal tone, as may occur during exercise, increase heart rate and enhance AV conduction. Even at rest neural factors seem to interfere with AV conduction. This was illustrated in Case I. Intense cerebral anoxia during asystole might have increased the sympathetic tone causing the observed tachycardia of the atria and final restoration of $\mathrm{AV}$ conduction. Reappearance of ventricular systoles led to restoration of cerebral blood supply with subsequent fall in sympathetic tone, bradycardia, and AV block. After treatment with isoprenaline, periodic asystole did not appear any more and exercise produced the expected shortening of the PR interval. 
When the heart cycle does not change during exercise, as happened in Case 60, a third factor, possibly effort-induced ischaemia, may be incriminated for the impairment of AV conduction. It is interesting that conduction during the supernormal phase (Moe, Childers, and Merideth, 1968) was not abolished by effort, as is seen in Fig. 3B. The RR interval including a supernormally conducted beat was longer than the next RR interval. However, the interval between the prematurely conducted beat and the next conducted $P$ is shorter than the next interval from the beginning of the QRS to the next conducted $P$. There is a possibility, therefore, that relatively early restoration of $\mathrm{AV}$ conduction after the supernormally conducted beats (Fig. $3 \mathrm{C}$ and E) could be explained by the dependence of the AV conductive tissue refractoriness on the previous cycle length (Brooks et al., 1955). The long PR interval of Fig. 3D apparently marks the relative refractory period of the AV conductive tissue.

These factors (heart rate, neural tone, and ischaemia) affecting the response of AV block to exercise are not adequate in explaining the basic finding of this study, namely that exercise tends to improve AV conduction in cases with a normal QRS but to impair it in cases with bundle-branch block. This finding cannot be coincidental, due to a different distribution of mild and severe degrees of AV block in the $\mathbf{2}$ groups, since there was no significant difference between the 2 groups in this respect.

Localization of the lesion might be the determining factor. According to Lenegre (1964), a lesion on both bundle-branches rather than on the bundle itself is often the cause of AV block. The presence of bundlebranch block on the electrocardiogram is an argument for the localization of the lesion at a low level toward the ventricles. This area is commonly considered as being out of the influence of neural factors that might improve AV conduction on exercise. Yet it may be influenced by tachycardia and by ischaemia, both of which tend to impair AV conduction.

The observation by Damato et al. (1969a, b) who recorded the activity of His bundle in normal and AV block cases may be relevant. They found that AV block might be due to a conduction defect either between the atria and the bundle of His ( $\mathrm{PH}$ interval) or between the latter and the ventricles (HR interval). An abnormally prolonged $\mathrm{PH}$ interval may be shortened by the use of atropine or isoprenaline. An abnormally prolonged HR interval is found in AV block cases due to block of both bundle-branches and may not be improved by the use of atropine or isoprenaline.

Contrary to the effect of atropine and isoprenaline, tachycardia produced by atrial pacing impaired conduction in both types of AV block (above and below the bundle of $\mathrm{His}$ ). If the relation between the cardiac cycle length and the refractory period were the determining factor for AV conduction defects, pacing of the atria at a high rate should have the opposite effect, since the refractory period becomes shorter with tachycardia, even not proportionally to the cardiac cycle (Brooks et al., 1955). The different response of AV conduction to the tachycardia effects of neural factors and pacing cannot be easily explained.

A possible way to understand this difference is to consider conduction as synchronization at a phase difference between the 3 parts of the conducting system, i.e. atrial, nodal, and ventricular (Van der Pol and Van der Mark, 1929; Segers, 1946; Moulopoulos, Kardaras, and Sideris, 1965; Moulopoulos and Sideris, 1967, 1969; Moulopoulos, Plassaras, and Sideris, I97I). Conduction is then 'depressed' by accelerating one part while the others remain unchanged, since the closer the idiofrequencies of two systems the easier synchronization is achieved. This acceleration of the atrial part alone by pacing impairs the whole AV conduction. Neural factors accelerate the atrial and nodal part alone, thus facilitating atrionodal conduction but impairing nodal-ventricular conduction. Hence, exercise facilitates AV conduction in cases with a lesion located in the atrionodal part of the conducting tissue (i.e. with a normal QRS pattern) but impairs AV conduction in cases with a nodal-ventricular defect of the AV conduction (i.e. in cases with a wide QRS pattern). The findings of this paper are in agreement with the above hypothesis.

\section{References}

Bauer, G. E. (1964). Bundle-branch block under voluntary control. British Heart fournal, 26, 167.

Brooks, C. McC., Hoffman, B. F., Suckling, E. E., and Orias, O. (1955). Excitability of the Heart. Grune and Stratton, New York.

Burch, G. E. (1962). Relationship of heart rate to cardiac output, work, power, and tension in man. Fournal of the American Medical Association, 182, 339.

Damato, A. N., Lau, S. H., Helfant, R. H., Stein, E., Berkowitz, W. D., and Cohen, S. I. (1969a). Study of atrioventricular conduction in man using electrode catheter recordings of His bundle activity. Circulation, 39, 287.

Damato, A. N., Lau, S. H., Helfant, R. H., Stein, E., Patton, R. D., Scherlag, B. J., and Berkowitz, W. D. (1969b). A study of heart block in man using His bundle recordings. Circulation, 39, 297. 
Lenegre, J. (1964). Etiology and pathology of bilateral bundle branch block in relation to complete heart block. Progress in Cardiovascular Diseases, 6, 409.

Manning, G. W., and Sears, G. A. (1962). Postural heart block. American fournal of Cardiology, 9, 558.

Moe, G. K., Childers, R. W., and Merideth, J. (1968). An appraisal of 'supernormal' A-V conduction. Circulation, 38, 5 .

Moe, G. K., Preston, J. B., and Burlington, H. (1956). Physiologic evidence for a dual A-V transmission system. Circulation Research, 4, 357.

Moulopoulos, S. D., and Anthopoulos, L. P. (I968). Reversible atrioventricular conduction changes during exercise. Acta Cardiologica, 23, 352.

Moulopoulos, S. D., Kardaras, N., and Sideris, D. A. (1965). Stimulus - response relationship in dog ventricle in vivo. American fournal of Physiology, 208, I54.

Moulopoulos, S. D., Plassaras, G. C., and Sideris, D. A. (I97I). Heart rate and intermittent WolffParkinson-White syndrome. British Heart fournal, 33, 513 .
Moulopoulos, S. D., and Sideris, D. A. (1967). Time relation between two pacemakers in atrial parasystole. British Heart fournal, 29, 758.

Moulopoulos, S. D., and Sideris, D. A. (1969). Effect of parasystole on ventricular response to atrial fibrillation. Cardiologia, 54, 257.

Scherf, D., and Dix, J. H. (I952). The effects of posture on A-V conduction. American Heart fournal, 43, 494 .

Segers, M. (1946). Les phénomènes de synchronisation au niveau du coeur. Archives Internationales de Physiologie, 54, 87.

Van der Pol, B., and Van der Mark, J. (1929). The heart beat considered as a relaxation oscillation, and an electrical model of the heart. Archives Néerlandaises de Physiologie de l'Homme et des Animaux, 14, 418.

Requests for reprints to Dr. S. D. Moulopoulos, Department of Clinical Therapeutics, School of Medicine, University of Athens, V. Sofias and K. Lourou Street, Athens, Greece. 